Available online at www.jmle.org

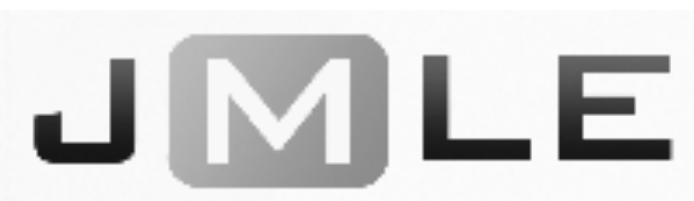

The National Association for Media Literacy Education's

Journal of Media Literacy Education 10 (2), 104 - 122

\title{
Fake or Visual Trickery? \\ Understanding the Quantitative Visual Rhetoric in the News
}

\author{
Rohit Mehta \\ California State University, Fresno \\ Lynette DeAun Guzmán \\ University of Arizona
}

\begin{abstract}
In online and video/television spaces, news media discourses incorporate multimodal design as a discursive move capable of steering meaning toward desirable implications. Around the 2016 U.S. presidential elections, while polarized news outlets made their positionality on the candidates obvious, more neutral or central news outlets revealed their preferences through subtle multimodal design choices. One of these design choices is using a quantitative visual rhetoric: persuasive multimodal moves that draw on quantification through visual, spatial, and textual manipulation - involving the choice of data representation, visual images, and illustrations, (im)balance between numeric and alphabetic texts, and general quantitative narrative. This quantitative visual rhetoric helps news outlets manipulate facts without lying with words, leaving the onus of misinterpretation on the readers/viewers. In this article, using examples from five types of media outlets - far-left, left-leaning, central, right-leaning, and far-rightwe share examples of design choices we found through multimodal analysis of their quantitative visual rhetoric during the 2016 elections. We share implications for media literacy education and civic engagement.
\end{abstract}

Keywords: quantitative rhetoric, visual rhetoric, news, multimodality, design

Media discourses are rich in multimodal texts (Lemke, 2009). Modes like written and spoken words, images, videos, descriptive representations, statistical plots and graphs, share space and time in news media discourses (Kress, 2003). These modes are interwoven to create, represent, and share meaning with a wider audience (Lemke, 2006). Words, numbers, and images are composed together, often intentionally, to convey information (Tufte, 1983). In online news outlets, the written word often dominates the design and compositional decisions (Leu, EverettCacopardo, Zawilinski, McVerry, \& O'Byrne, 2012; Cleveland \& McGill, 1984). In television and video-based news outlets, the spoken word of the presenters and experts often takes the onus of carrying the core of the meaning. Still, in both these spaces, visual modes play a critical role in shaping meaning (Kress, 2003; Tufte, 1983). Design choices for media websites, for instance, define how written words are displayed, the stylistic choices of font-face, colors, background, 
menu options, ad placement, and screen space occupied by videos and images (Holsanova \& Nord, 2010; Kress \& van Leeuwen, 1996; Tufte, 1983). The choice and balance between words and numbers - and the choice of images and video, their size and duration, nature of the content and frequency of advertisements, and multimodal rhetorical moves - shape user experience, meaningmaking, and perception of truth and distant reality (Foss, 2004; Kress, 2003; Kress \& Van Leeuwen, 1996; Lemke, 2009).

An expectation from journalistic media outlets, ideally, is of fairness (Peters \& Broersma, 2013). The information shared on popular news outlets is often expected to be factual and accurate (at least before "fake news" became a popular term) (McNair, 2017). The multimodal rhetoric that shapes the user experience on these news outlets also carries the burden of veracity and accuracy of information. When this rhetoric is manipulated, the veracity can be brought into question as well. This rhetoric, however, is made of carefully chosen multimodal texts (Kress, 2003). Design is a part of the rhetoric of communication, may it be visual, verbal, or even mathematical (Kress, 2004). Therefore, when questioning the veracity of information, one needs to identify and tease apart the rhetoric of the journalistic media, which begins with the dissection of the design choices made with multimodal texts and discursive moves (Jewitt, 2014).

\section{LITERATURE REVIEW}

\section{From Weaving Lies...}

In the realm of meaning-making in journalistic media, the onus of carrying the truth is placed on written and spoken words. Generally, people tend to believe that lies are told with words and, hence, focus on words to catch lies. In journalistic, political, and legal discourses, the choice of words and the subtle rhetorical moves to twist meaning are often seen as preferred conduits of lies without getting accused of lying. For instance, on his involvement with Monica Lewinsky, Bill Clinton rationalized to the grand jury that he was not lying to his top aides when he said, "There's nothing going on between us." He told the grand jury that:

It depends on what the meaning of the word 'is' is... if 'is' means is and never has been...that is one thing. If it means there is none, that was a completely true statement.... Now, if someone had asked me on that day, are you having any kind of sexual relations with Ms. Lewinsky, that is, asked me a question in the present tense, I would have said no. And it would have been completely true. (Starr, 1998)

Despite (or because of instances like) Clinton's rhetorical distortion, words and numbers are the ones that are closely surveyed and monitored. If a sequence of words does not align with what can be factually proven to be true, one can be prosecuted for lying. For example, in 2013, famous Fox News presenter, Bill O'Reilly, was caught lying discussing the Falkland War when he said, "My photographer got run down and then hit his head and was bleeding from the ear on the concrete. And the army was chasing us ... I dragged him off." Shortly later, the aforementioned photographer countered his words (Arana, 2015):

"I never fell nor was I bleeding out my ear at any time during my Buenos Aires assignment," Ignacio Medrano-Carbo said. "I do not even recall Mr. O'Reilly being near me when I shot all that footage nor after I left the unrest at Plaza de Mayo that evening. But 
it is not uncommon to be separated from your reporter during a disturbance such as that one."

While the controversy petered off, what is interesting about this example is how the counter by the photographer attacked Bill O'Reilly's specific words, such as "got run down," "bleeding from the ear," and "I dragged him off." The photographer could then provide stories that contradicted O'Reilly's words, thereby accusing him of lying without using the word "lie."

Similarly, NBC presenter, Brian Williams was caught lying on a story he had been retelling for 12 years about being in a helicopter that was shot down in Iraq. But later, when refuted by a veteran who was actually in the helicopter, Williams admitted to being in a different helicopter 30 minutes behind the one that was shot down. Once again, he had exaggerated the sequencing of his word and manipulated them over a decade to reach a point where a co-experiencer could challenge them as blatant lies. A helicopter was shot down. Brian Williams was present during that time. He was in $a$ helicopter. But, he was never in the helicopter that was shot down.

\section{...To Designing Lies}

Lying with words and numbers is difficult to get away with, especially when those are the only modes accessible to share a narrative. It is, however, comparatively easier to manipulate clarity, facts, and truth with quantitative visual texts and quantitative rhetoric that supports such visualization-specifically, charts, graphs, visually represented quantitative concepts such as percentages, difference, change, probability, predictability, and chance (Kostelnick, 2007; Tufte, 1983) - and even use of quantitative language that implies a spatial or visual arrangement of numbers without the use of numbers. For example, during his speeches and on social media, Donald Trump frequently uses quantitative words such as "a lot of," "many," "enough," etc. to create an impression of a numeric value without having to present a number (see Figure 1). While some choices (such as Figure 1) are more obvious as quantitative rhetoric, other choices can be subtle and may need better training to understand.

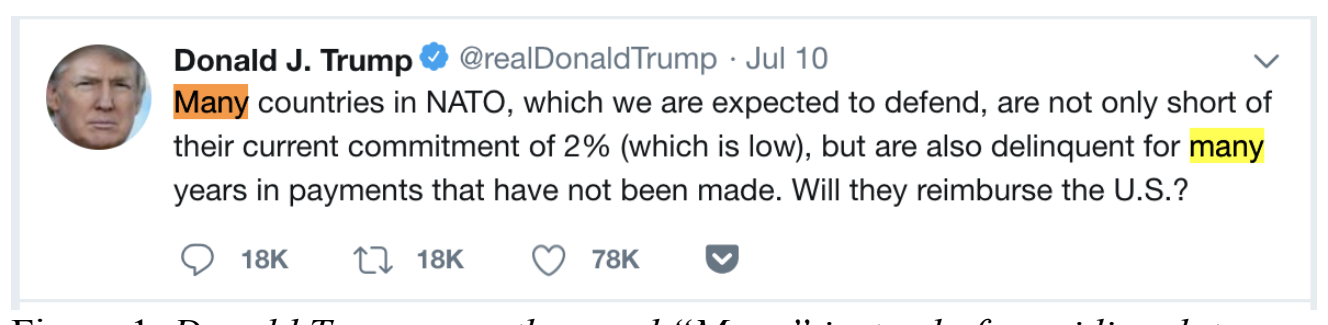

Figure 1. Donald Trump uses the word "Many" instead of providing data.

McNair (2017) argues that such quantitative manipulations are common among journalistic media outlets, too. Partial and carefully curated information is used to design a quantitative rhetoric that helps emphasize or exaggerate favorable points without having to lie with words. While others have explored quantitative rhetoric to understand how quantified information is used in argument and persuasion (e.g., Bookstein, 2009; Craig, 2017; Schmit, 2010), our focus on quantitative rhetoric specifically includes spatial information. In other words, we are interested in persuasive multimodal moves, as explained by Kress (2004) and Tufte (1983), that draw on quantification through visual, spatial, and textual manipulation. When using visual quantitative modes, such as scales, axes, chart and graph types, extracting information requires viewer to be able to perform mental-visual tasks that involve teasing apart complex modal affordances of the variables represented (Cleveland \& McGill, 1984; Gibson, 2014). While graphical visualizations 
are often considered signs for these mental-visual tasks, quantitative language (such as the one shown in Figure 1) can also demand mental visualization to process quantitative meaning. What does many mean? How many is many? Multimodal examples like these present complex challenges for media literacy education.

\section{Quantitative Visual Rhetoric}

The complexity of manipulating multimodal texts, especially quantitative and visual texts, has become a common practice among journalistic media outlets - perhaps more among some than others (McNair, 2017). Fox News, for instance, during Obama's presidency, frequently undermined his achievements and exaggerated his shortcomings by focusing on a rhetoric that served their political dispositions. But, what is more interesting to this paper is their manipulation of the quantitative visual rhetoric to corroborate their narrative. Figure 2 shows a television news graphic from 2014 by Fox News where the y-axis is skewed and labels are omitted on a chart that displayed number of enrollments for the Affordable Care Act (ACA), with the intent to visually exaggerate the gap between expected and actual enrollments.

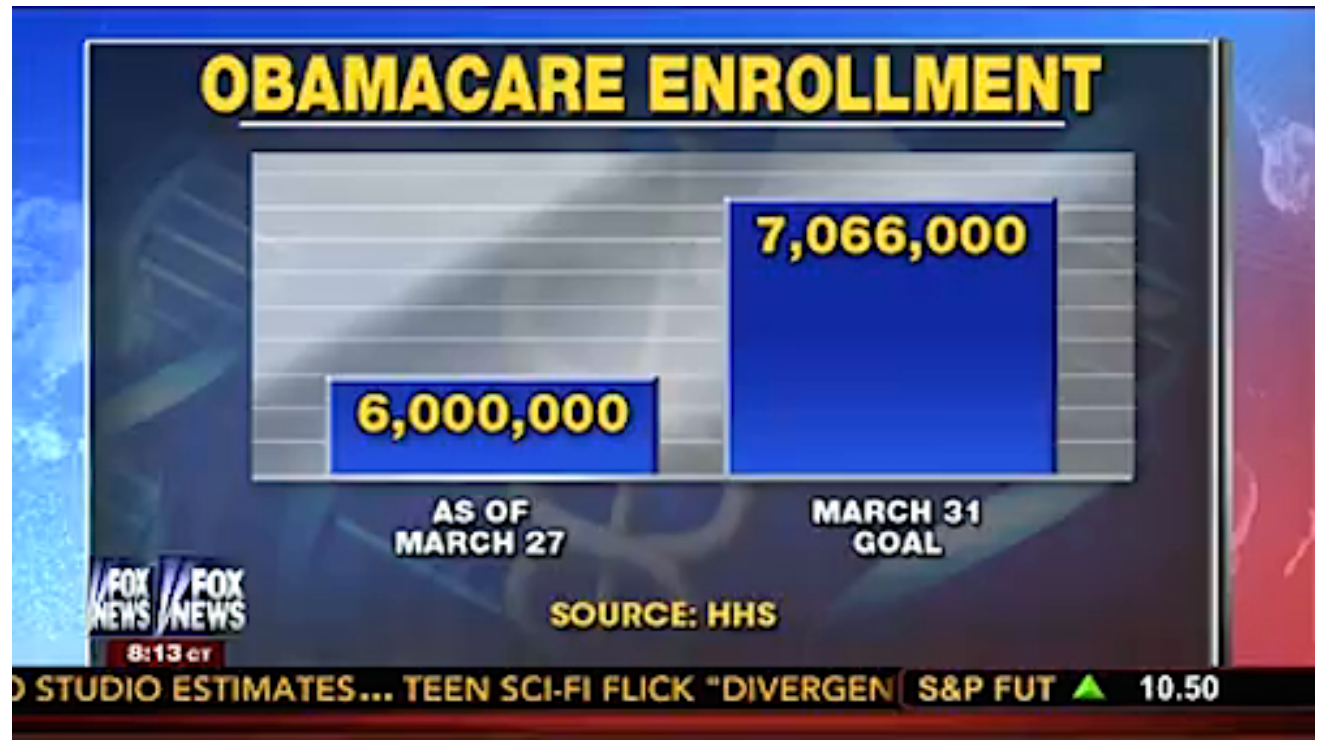

Figure 2. The original Fox News bar chart cropping y-axis and omitting labels. Source: MediaMatters.org

There are several ways to dissect this graph and point to the problematic manipulation of quantitative concepts. Other arguments can be made regarding the violations made in this figure as it violates basic principles of graphical representation (Tufte, 1983), but instead of statistical literacy we focus on a specific aspect to underscore the importance of quantitative rhetoric. In MSNBC's reaction to Fox News, they called out this manipulation and questioned the relative size of the two bars, asking, "Since when is six million less than half of seven million?" Figure 3 shows a screenshot of this segment. Here, like our logical reaction, MSNBC is questioning the absence of data labels. But, they are (rightfully) assuming that the baseline, or x-axis, used by Fox News follows graphical standards and starts at where y equals zero (Tufte, 1983). With this assumption, MSNBC was pointing out a manipulated use of visual space to exaggerate difference. That is, the bars in this chart are unfairly scaled because it appears that the left bar of 6,000,000 people is less 
than half of the right bar of 7,066,000 people, which is not true. MSNBC highlighted this unfair scaling - with another flawed graph (Figure 3) - by adjusting the left bar ('factoring in reality') so that both quantities could at least be compared on the same scale where the increments between each line is around 875,000 people.

We argue, however, that Fox News instead disregarded agreed upon design norms and chose to begin the baseline at around 5.5 million and cropped out the rest of the graph as irrelevant. In other words, they chose to show us only the top portion of a bigger graph to exaggerate the gap between the two numbers because while the mathematical difference between two numbers is a fact, their perceived difference is relative. Although we could read the increments between each line as 200,000 people to give us the difference between these two bars, this image unfairly manipulates scale by not displaying most of the bars to compare overall relative size. Most importantly, Fox News circumnavigated lying by choosing to omit the legends and a label for the $y$-axis, which hides the careful design choice of zooming in to exaggerate the difference between 6 and 7 million.

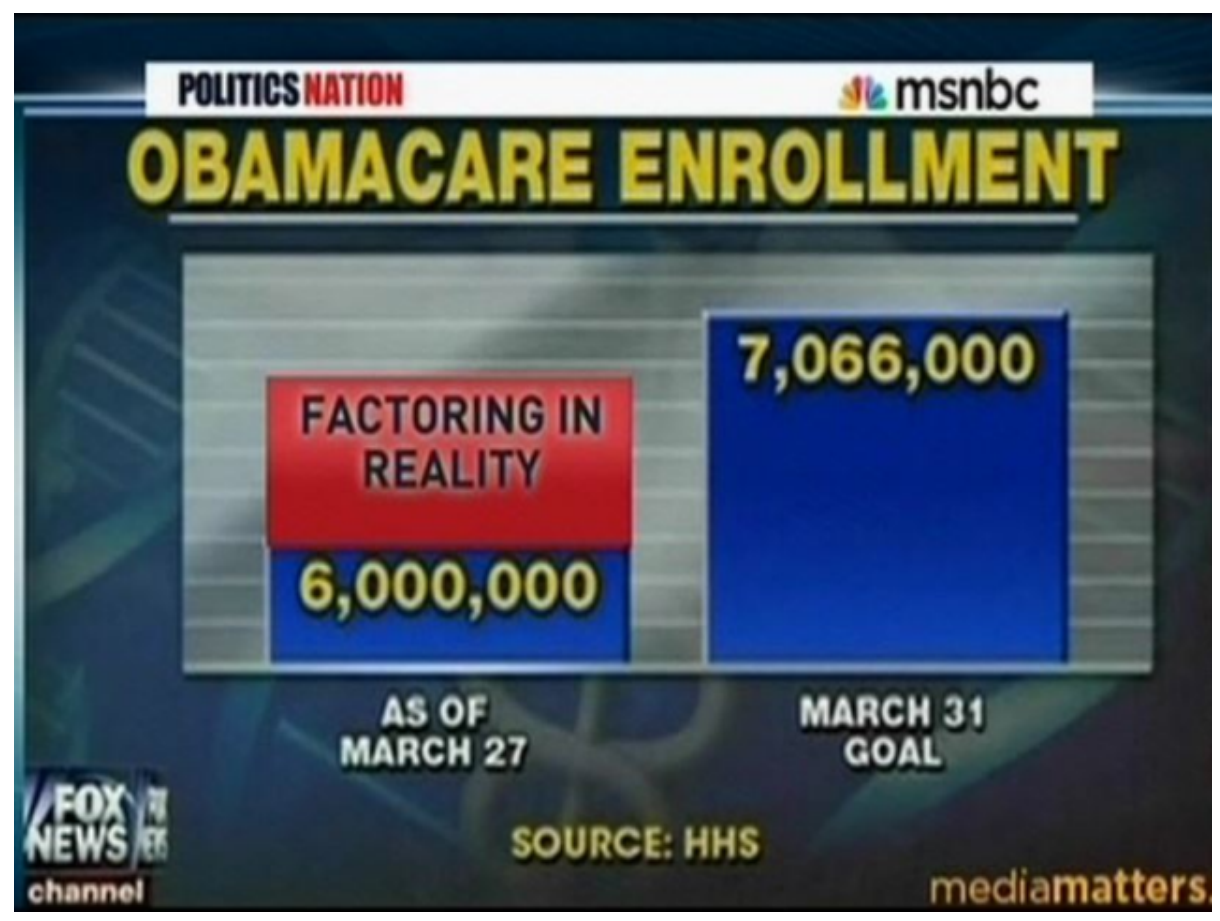

Figure 3. MSNBC questions the original chart from Fox News, factoring in the actual size of the bar assuming the baseline to be at zero. Source: MediaMatters.org

MSNBC accuses Fox News of lying with quantitative visuals because they assume Fox News is following the grammar of visual design and graphical representation (Tufte, 1983). Our explanation shows how Fox, instead, abused the modal affordances of a bar chart without, technically, lying. When it is easier to catch people lying with words and even with visual manipulation done using computer software such as Adobe Photoshop, it is frustrating for viewers to label fabrications created by dishonest design choices, especially those that are quantitative in nature. Quantitative rhetorical moves make it more difficult to label media outlets as fake. This Fox News example is one of the many reasons why it is important for media consumers and media literacy educators to look beyond traditional forms of literacy that center attention on words, and 
instead give equal value to visual, spatial, and other types of modalities that shape user experience and meaning in the media.

Before and during the 2016 U.S. presidential elections, polarized media outlets, like Fox News, made their positionality on the candidates obvious through rhetorical moves similar to the ones we have just described. More neutral or central media outlets, however, revealed their preferences in subtler ways through their multimodal design choices. These choices included visual and spatial design, data representation, content and positioning of images and illustrations, and other visual texts, especially those quantitative and statistical in nature. Irrespective of the political dispositions of the media sources, quantitative visual texts played a crucial role in creating a preferred narrative that allowed media outlets to manipulate facts without lying with words, leaving the onus of factual interpretation on the readers/viewers (McNair, 2017).

\section{METHOD}

In this article, we share our multimodal analysis of quantitative visual rhetoric in the news during the 2016 presidential elections. We use examples from five types of news outlets representing different positions on the political spectrum ranging from extreme left to extreme right. We studied the use of persuasive visuals and quantitative rhetoric that draw on quantification through spatial and statistical manipulation and what this means for media literacy in an era of alternative narratives and facts. Based on multimodal analysis, we present key design choices to discuss implications for media literacy education and civic engagement. We also offer a discussion for practice to detect quantitative manipulation in the news. These solutions involve multimodal analysis of quantitative visual rhetoric, including examinations of design choices such as spatial arrangement, type of charts, scale manipulation, distribution of visual information, which have implications for meaning-making (Kress \& Van Leeuwen, 1996).

To study examples of quantitative visual rhetoric across media, we begin by framing a researchable question:

RQ: In what ways do multimodal design choices affect quantitative rhetoric and meaning across popular online news outlets?

To answer this question, we started by delineating a replicable method of charting rich sources of online news items that show possibilities of manipulation with multimodal texts. Our goal was to find, across media outlets, examples of quantitative visual rhetoric that people engaged in during the 2016 presidential election. We could then conduct a multimodal analysis of each of these examples to understand how design choices affected the rhetoric and meaning. Finding examples that meet these criteria meant finalizing a short list of samples. In multimodal analysis, Kress (2003, 2004) and Jewitt (2014) have shown that identifying modal affordances of key examples are more important than the size of the sample.

We, too, focused on finding a handful of key examples from each news outlet that could offer us rich data to analyze their inherent design choices. First, we identified five types of media outlets that spanned the political spectrum-left-bias, left-center, center, right-center, and rightbias - to cover a range of possible examples of media bias, if any. Second, we used Amazon's popularity checker (https://www.alexa.com/siteinfo) to prepare a list of the most popular news outlets that have at least 50\% readership/viewership in the USA to assure relevance to the United States. Third, we used Media Bias Fact Check's website (https://mediabiasfactcheck.com/) —an 
independent media outlet focused on educating public on media bias and "deceptive news practices"- to sort the popular media outlets based on their biases on the political spectrum. Media Bias Fact Check (https://mediabiasfactcheck.com/methodology/) uses a strict method to rate (on a Likert-type scale of 0 to 10 ranging from least bias to extreme bias) all media outlets for their biased wording and headlines, credibility of sources, story choices, political affiliation. Then, the aggregated scores determine where the respective outlet falls on the political spectrum between extreme left and extreme right bias with least bias placed in the middle.

The final five journalistic outlets that met all criteria and checks were: CNN (left-bias), New York Times (left-center), USA Today (center), Wall Street Journal (right-center), and Fox News (right-bias) - the top outlets from each of the five categories on the political spectrum (where popularity was determined by alexa.com). All following data for rank and readership in the U.S. were recorded at the time of the analysis after the 2016 presidential election in the months of December and January. For left-bias, we also reviewed Huffington Post, which had a $71 \%$ of readership in the U.S., along with CNN, with $65.5 \%$ readership. Out of the two, we selected CNN for the final analysis because of its popularity over Huffington Post (CNN ranked at 15 versus HuffPo at 30 in the U.S.) and frequency of quantitative rhetoric that was often absent on Huffington Post, which relied more on lists and chunking information for readability. For leftcenter, we examined New York Times, which is open about its bias and keeps a record of its political positionality over the years. The New York Times was ranked at 21 with a $66 \%$ readership. For center, we examined USA Today, which was considered to be a leading media outlet under the least-biased category on Media Bias Fact Checker. They ranked at 76 and 76\% readership. For right-center, we examined the Wall Street Journal, ranked at 101 with a $58 \%$ readership. Finally, for right-bias, we examined Fox News, ranked at 34 with $80 \%$ readership.

Finally, having listed our top five media outlets, we needed to select their popular articles/pages that used quantitative visual rhetoric. We used BuzzSumo's advanced popularity and visit tracker (http://buzzsumo.com/) to gather the top visited news stories and pages for each outlet. This website allowed us to look at each article during the Presidential elections and sort them by "most popular" and "most shared." We reviewed top articles from a six-month time period leading up to the election, from June 1, 2016 through November 30, 2016. Starting from the top of sorted lists, we read each article carefully for examples of quantitative visual rhetoric. Opinion pieces and special interest stories that received a lot of popularity were often heavy on written word and qualitative narratives than quantitative rhetoric.

Searching for popular news articles from each outlet on the political spectrum that fit under the criteria of 2016 election and quantitative rhetoric narrowed down search results to some key examples. Generating a large dataset for such niche topics is not only difficult, but also not appropriate given the importance of teasing apart the modal affordances of a smaller set of examples (Jewitt, 2014). We prepared a final list of sample articles after discussing whether each article fit the criteria of including a quantitative rhetoric. We finalized two articles per outlet, adding up to a total of ten articles that we further analyzed taking a multimodal approach to tease affordances of inherent design choices (Gibson, 2014; Kress, 2004; Jewitt, 2014).

\section{Multimodal Analysis}

For each article, both the authors met and co-analyzed the multimodal affordances and how they influenced the overall rhetoric and meaning, taking detailed notes and identifying emerging patterns of design choices across the spectrum. Following Tufte's (1983) standards of graphical 
design and Kress $(2003,2004)$ and Jewitt's (2014) method of multimodal analysis, we started to tease apart spatial modalities, such as height, width, axis, colors, size, position, supporting language, interactiveness, etc., for each example. We used these modalities to understand their affordances and how they could influence the overall rhetoric and meaning-making. For instance, as seen in the Fox News example in Figure 2, deleting the axis makes all the difference in the interpretation of the graph. If we label the baseline as 5.5 million, that too will transform the graph. Over several iterations of analyzing the samples, our goal was to find the nature of commonly occurring design choices that media outlets in our sample set used and how these choices shaped meaning. Upon analysis, we identified four key design choices made by the five outlets that have implications for media literacy education, which we share next.

\section{FINDINGS}

Through our investigations of the existing quantitative visual rhetoric across multiple news outlets, we focused on how these journalistic media represented, implied, and visualized numbers - not simply that numbers were used. In process, we identified four key design choices, which are as follows: (a) spatial manipulation and biased design; (b) fantasizing with probability; (c) manipulation through data extrapolation; (d) avoiding numbers when inconvenient.

In this section, we share each of the four design choices in further detail to explore the possibilities and affordances of lie, deception, and manipulation that may have contributed to the popular social experience of "fake news." In each of the four design choices, we used examples from our final sample articles to explain the modal affordances of the choices themselves and how they contribute to the rhetoric of fake news. In each case, we attempted to dissect the nuances of the quantitative visual rhetoric and what it means for meaning-making. We must note that our focus is not centered on the veracity of the stories or descriptive data but rather the affordances of the design and rhetoric invoked.

Across the spectrum of our sample articles, we studied affordances for each of the four design choices. The extent of manipulation of these affordances, however, varied. For instance, we found Fox News' manipulation through data extrapolation to be more blatant and heavily right leaning than CNN. Fox News tweaked with the modal affordances for quantitative language, too, but in ways that can be considered unnoticeable or ineffective in showing bias.

\section{Spatial Manipulation: Designing with Disposition}

The news media outlets on the left- and right-center in this study (i.e., New York Times and Wall Street Journal, respectively) both seemed to have used web design as a strategy to carefully create a quantitative visual rhetoric that favored their political dispositions. These dispositions become more obvious when compared with a relatively central outlet, such as USA Today. For example, in an analysis of Trump's involvement with lawsuits as a businessman, Penzenstadler and Page (2016) presented an investigative report that provided a breakdown of data, which is shown in Figure 4. In an effort to make fair comparisons, USA Today authors examined Trump's legal involvement compared to five top real-estate business executives. Without invoking sensationalist language to accompany visual representations, the authors allow readers to process the data for comparisons and meaning-making. The design choice shown in Figure 4 makes it difficult to infer their political dispositions as it does not contrast his data with other political figures. Additionally, the language accompanying the visuals was plain, transparent, preemptively addressing questions that may arise. The interactive feature took readers from one graph to another 
that helped visualize the scope of Trump's lawsuits without implying whether that is normal or abnormal for a businessman or politician in his position. None of their rhetoric moves tried to appease readers with a preferable outcome or scenario, unlike the New York Times and the Wall Street Journal.

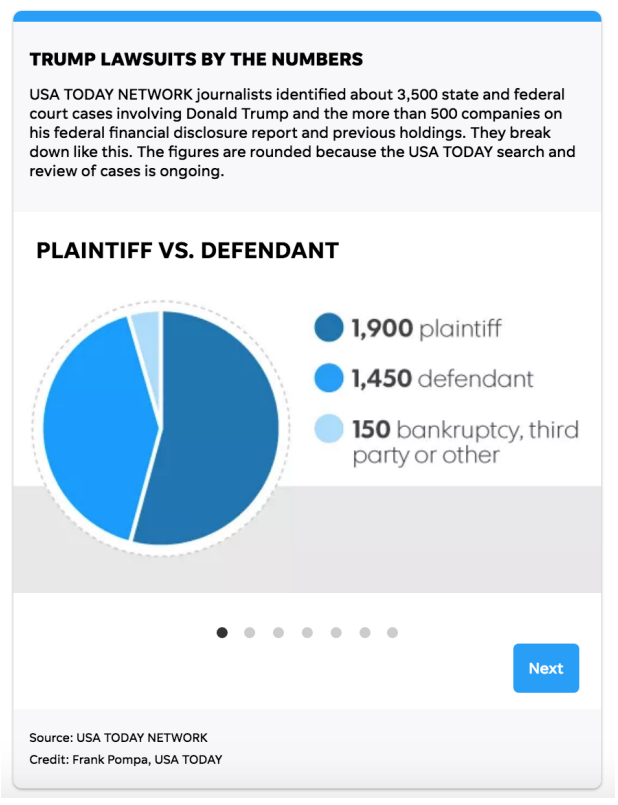

Figure 4. Screenshot of visual display that presents a breakdown of Trump's 3,500 court cases. Source: Penzenstadler \& Page, 2016

In our analysis of the New York Times and Wall Street Journal, we found the most popular and widely shared articles to be their respective coverage on the contest between the democratic and republican nominees for the presidential election: Hillary Clinton and Donald Trump. Taking each in turn, we found that both outlets used similar subtle design-based approaches to create a visual rhetoric that used quantitative principles to imply preferences. For example, in one of the New York Times's most popular and widely-shared article/webpages during the 2016 presidential elections, they provided an interactive data-saturated space in which their readers could click and play multiple possibilities of win and loss combinations (Katz, 2016). Figure 5 shows an example from this series of infographics, with included various interactive graphs and charts, giving agency to the users, who could manipulate information to change the hypothetical outcome of the election and see possible paths to win for the candidate of their choice.

These charts included: (1) trend of winning chance for each candidate over the latter half of 2016, (2) change in winning chance in key states, (3) state-by-state comparisons, (4) news media and survey source comparisons, (5) state-by-state and survey source comparisons, (6) likelihood of each possible outcome including 500 odd combinations of the electoral votes, and (7) all possible paths to the White House for each candidate, starting with the choice of assigning a win to each of the following key states: Florida, Pennsylvania, Ohio, North Carolina, Virginia, Wisconsin, Colorado, Iowa, Nevada, and North Hampshire.

On first glance, the idea of offering readers a chance to imagine multiple possibilities seemed fair and unbiased as it allowed all possible readers to play with data. However, on further 
analysis, we deemed two foundational questions crucial. First, who is the intended audience? Second, if there is a subtext, what is it?

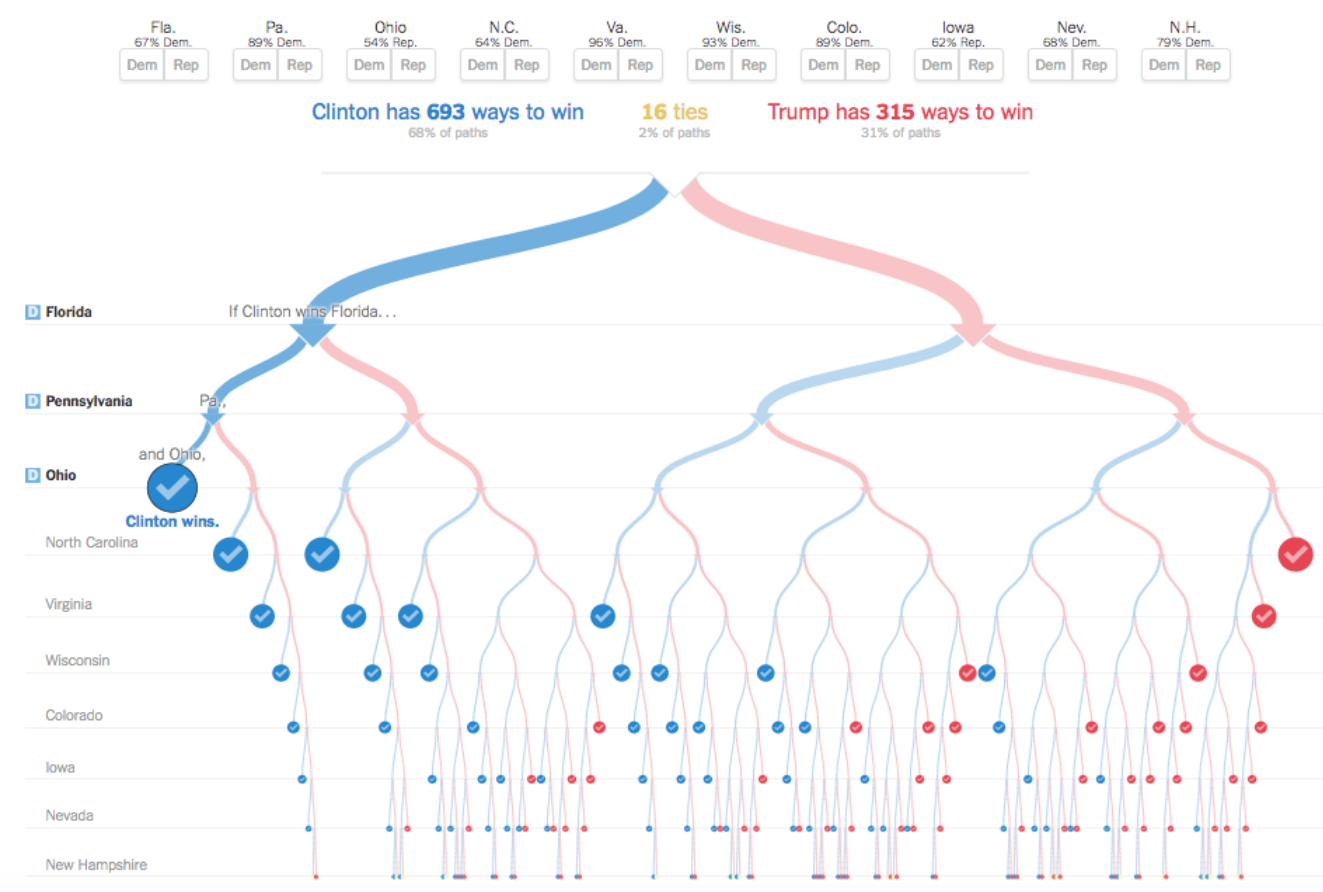

Figure 5. Screenshot of interactive diagram where readers can manipulate possible election outcomes from 1,024 pathways. Source: New York Times

The stance of convincing can be seen in particular design and rhetorical choices. Along with the interactive diagram, we found that the surrounding text shed light on the New York Times's position: “[illustrating] Mr. Trump's challenging path to the presidency." Readers are encouraged to "control the outcome" for ten key states, manipulating the 1,024 possible combinations for an imagined outcome based on collected data that supposedly reflect aspects of reality. While this interactive diagram seems to provide agency for readers to choose possibly pathways, it is still constrained (Rawlins \& Wilson, 2014). Not only does the designer control the polling data used, but also the rhetorical message in the surrounding text that suggests a challenge for Trump's path to victory.

Analyzing further into the quantitative rhetoric, we investigated the visual components that carried favorable meaning layered in the design and choice of charts and graphs. Each type of chart provides affordances for users to manipulate meaning that is convenient to them. A bar graph might allow the user to compare a variable across multiple instances. But the choice of those instances depends on the creator who can warp the message for the readers. Statistical and quantitative rhetoric, which deals with visual representation of numbers, might be viewed as an objective or unbiased stance. But when contextualized by the accompanying text and possible design choices, organizational and representational choices of data reveal a disposition as well. For example, the chart that displayed likelihood of each possible combination of electoral votes was labeled "Electoral votes for Hillary Clinton," thereby making it a chart of number of ways Donald Trump can lose. Similar visual and statistical space was not given to his possibilities of winning. 
Similarly, at the Wall Street Journal, in an article that focused on linking corruption with Clinton in multiple possible ways, there was an embedded GIF of an interactive electoral college map (Barrett, 2016). Readers could click on the map and assign the states to the candidate of their choice. Interestingly, in the GIF, which was running in a continuous loop, showed Clinton's blue states turning to red by clicks of a moving mouse icon. Without any direct relation to the article itself (which was about possible charges of corruption), the newspaper offered an escape to its readers - who might have felt direr than New York Times readers-through the interactive map conveniently placed within the article like an advertisement.

Because both the New York Times and the Wall Street Journal are both open about their political dispositions, their respective narrative choices were not surprising, nor were they blatant manipulations of the standards of graphical representation and quantitative rhetoric like Fox News (as we explain later in this article). What is interesting, though, is the subtler use of visual design to appease anxious readers by offering them interactive data-driven charts to play with and fantasize possible futures. Using quantitative visual rhetoric, especially when combined with concepts of probability and predictability, offers outlets that may wish to be perceived as objective or leastbiased an option to conceal dispositions in design.

\section{Fantasy and Probability}

The difference between possible and probable is a crucial one, especially when speaking in the context of predictability. It was possible for Hillary Clinton to win the election. It was also possible for Donald Trump to win the election. But, these statements do not appease people of their anxieties for unpredictable social futures. People may want to know more than what they know themselves, so the news outlets seek statistical help and use probability to share the likelihood of every occurrence, which can be seen on data-driven websites like NY Times, FiveThirtyEight, and Fox News. Ultimately, the outcomes that fit the overall narrative and political dispositions are underscored as these statistics are created.

Data-driven reporting is often conceived as being number-based and, therefore, objective and unbiased (Porter, 1995). Reporting the numbers, then, might be equated with reporting the facts. So, when the New York Times a news report shared 85\% chance of winning for Hillary Clinton, it could be considered as a fact by some. Figure 6 shows a screenshot from an article where the probability of winning is calculated next to a face shot of each candidate. This is where design choices become important. How the numbers are shared online can shift the intended meaning (and subsequent sense-making). In the New York Times, for example, in a scenario where the current polls showed an $85 \%$ chance of winning for Hillary Clinton, users could have created a quantitative rhetoric around this number to favor a message that fits their agenda. They could have even varied from left-leaning to right-leaning storylines in many ways, such as:

a. "Hillary Clinton has an $85 \%$ chance of winning"

b. "Hillary Clinton has a fighting $85 \%$ chance of winning"

c. "Crooked Hillary rigged polls to show an $85 \%$ chance of winning"

d. "Donald Trump still in the race with a $15 \%$ chance of winning"

e. "A victory by Mr. Trump remains possible: Mrs. Clinton's chance of losing is about the same as the probability that an N.F.L. kicker misses a 37-yard field goal." 


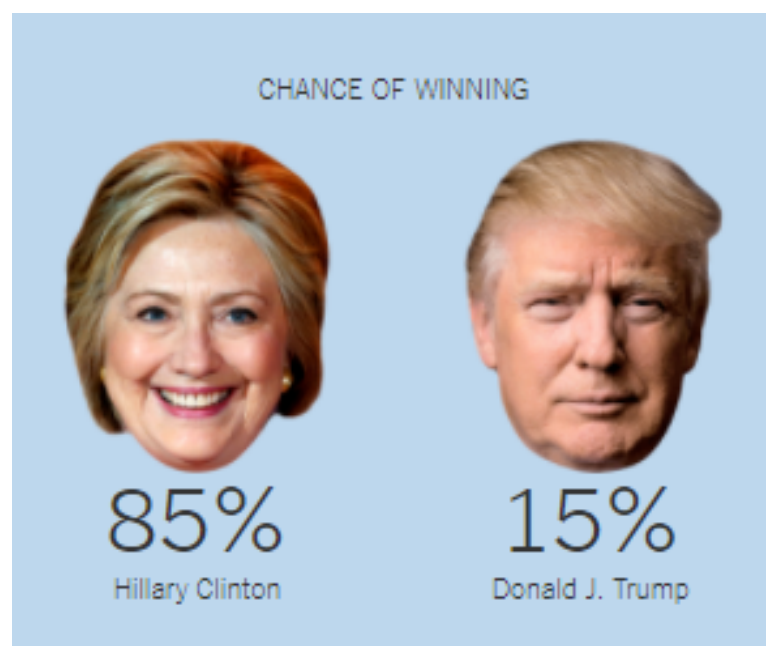

Figure 6. Screenshot from a New York Times article showing the chance of winning accompanied by the faces of the candidates. Source: Katz (2016)

The last sample (e) was an actual statement used in the New York Times article that we examined (Katz, 2016). The only instance in the article that included Trump in a possibility of winning was intertwined with the chance of Clinton losing explained with the help of a popular experience among Americans of missing a 37-yard field goal. Although both statistics were the same $(85 \%)$, it was an interesting choice to reference professional sports - an activity that can elicit strong affective reactions from fans. Particularly with professional sports like the National Football League (NFL), players perform at such a high caliber that might complicate how ' $85 \%$ ' is made sense of in connection to the context of a presidential election. A victory by Trump might have been unlikely but was not impossible, just as a missed 37-yard field goal by a professional football kicker is unlikely but not impossible. In some ways, it raises the question: Is Trump politically as good as a professional football player?

As discussed in the New York Times example, readers could play with statistical principles of probability and predictability to create a fantasyland with outcomes that they desired. The Wall Street Journal created a similar space in one of their most popular articles during the elections. In the article titled "FBI in Internal Feud Over Hillary Clinton Probe," the Wall Street Journal used large numbers to create a narrative of a corrupt politician leading in the presidential race (Barrett, 2016). Starting with the subheader, "Laptop may contain thousands of messages sent to or from Mrs. Clinton's private server," the Wall Street Journal used the word "thousands" as quantitative language to plant an image of an overwhelming number of emails. When we looked across news outlets, we found that "thousands" was the quantitative word of choice when raising allegations. "Thousands" is a reasonable number to be possible, which makes it believable. If found untrue, this number can also be considered a reasonable error. For instance, if we replace the word "thousands" with "millions," the claim becomes absurd. "Millions of emails" is too large a quantity to grasp as reasonable for this context and raises doubts about the authenticity. "Hundreds," in contrast, feels too low to be problematic. "Thousands" offers a decent range between 1001 to 999,999 and keeps the focus on the topic rather than shifting it to the news organization. Again, this quantitative language implies a spatial arrangement of numbers without the use of numbers or visuals - creating a quantitative visual rhetoric that underscores particular narratives. 
Such narrative was common throughout the Wall Street Journal article (Barrett, 2016). What becomes more interesting is that, in the article, the use of quantities is more numeric than word-based. Embedded in the article, readers can spot larger numbers like "650,000 emails," and " $\$ 467,500$ in campaign funds" easily because they stand out from the rest of the article and are placed in the segments that specifically speak to possible corruption. We argue that such design choices are among the subtler forms are quantitative visual rhetoric because it does not even register as visual rhetoric with most readers.

Embedded in this same Wall Street Journal article was the interactive electoral college GIF mentioned in the previous section. Positioning these choices side-by-side, the authors produced a quantitative visual rhetoric that suggested Hillary Clinton's unfavorability. Consequently, readers are provided an opportunity to guess the electoral college outcome and fantasize about her losing the election.

But, what was more interesting to us was the statistical and quantitative language that is used carefully to keep a claim at a safe distance from a lie. The choice to use probabilistic language such as "may," "likely," and "possible" - that usually add nuance to statistical discussions - have been used by some media outlets to make damaging claims more authentic, while saving the news outlet of responsibility. This puts the onus of meaning on the reader, who needs to be conscious of the quantitative rhetoric that is used to warp truths.

The specious use of concepts of statistics and probability raise a bigger concern. While experimental probability estimates probability of occurrences based on existing data, theoretical probability attempts to mathematically calculate the chances for each occurrence. This is crucial to understand because what could mathematically happen may not actually happen. Even with a simple coin toss, just because head and tail have an equal probability of occurring, that does not mean that after a coin landing on "heads," the next has to land on "tails." In probability, fairness is a theoretical assumption.

These arguments are important to understand because they influence our understanding of everyday predictability and probability in complex social scenarios. Just because Donald Trump has a $15 \%$ chance of winning, that does not mean he cannot win. Once he wins, all that matters is that he won. His chance of winning is a theoretical, mathematical calculation and an estimate. It does not influence the outcome of the future. It does not control what people will end up doing. Because unlikely is not impossible, people can always argue that it is still true that he had a low chance of winning and with his win a less likely event took place. But, for a shared reality, it is irrelevant what possible events could have happened. What matters is the one event that did happen. For readers then, probability and statistical models become fantastic escapes. So why produce these statistics at all? We argue that a part of the reason involves fantasizing, which can be an intentional design choice in produced media. In the next two sections, we explore how outlets drew on statistics and rhetorical moves to advance storylines.

\section{Manipulation through Extrapolating Data}

As we have mentioned in the introduction, an important part of quantitative visual rhetoric is the quantitative language that helps manipulate a mental visualization. Word choices for numeric values are interesting design choices that create a visual rhetoric without visual manipulation. Media outlets might manipulate storylines by extrapolating data. In other words, reports might include carefully selected data points to imply an exaggerated scope of the phenomenon or issue. For example, a Fox News report on voter fraud reported single examples from four states to generalize a sense of voter fraud in the United States (Fox News Insider, 2016). 
The online article was accompanied by a video interview segment that appeared on the television show, Fox \& Friends. In the first state example, 20 deceased people and "more than 1,000 noncitizens in Virginia [were] registered to vote" and the commentator in the video clip noted that this count did not include Fairfax County and Arlington County, which were two of the most populous areas in the state. She closed with comments suggesting that this "really would have turned Virginia blue in recent months," despite not having any evidence to back up this claim.

One notable observation from this example is the absence of how the count of 1,000 relates to the state population of Virginia (over 8 million) or the number of registered voters in the state (over 5 million). From those omissions, the commentator was able to extrapolate the specific example to suggest a massive problem, even though the relative percentage of the data given is about $0.02 \%$ for 1,000 out of 5 million registered voters. She does this by stating that these voter fraud counts do not even include areas with substantial population, and ultimately, implying that there must be more counts of voter fraud in these larger populated areas. The omission or lack of data from areas with substantial population is used as an advantage to make predictions about the areas without relevant evidence.

A second example from this report was that in Pennsylvania there may be more than 43,000 voters who are registered twice and "more than 700 Pennsylvania voters might have cast two ballots in recent elections." Similarly, this count is reported in isolation from the full contextPennsylvania is a state with over 12 million people of which 8 million are registered voters. Putting 43,000 in relation to the number of total registered voters ( 8 million) is around $0.53 \%$. Furthermore, reporting statistics on voter registration alone is not the same as actual duplicate votes. There could be multiple legitimate reasons for duplicate voter registrations (e.g., recently moved to another state, delay in record updating), and that count does not represent fraudulent votes cast. Quite simply, voter registration is not the same as voting. Again, this example follows a similar extrapolation as the previous example in Virginia: the reporters imply that this is a problem of scale in the United States. Quantitative rhetoric in this stance was made more visible as the commentator verbally offered a visualization by stating, "There's a lot more. Tip of the iceberg." Not only does the quantitative language ("a lot more") imply a spatial arrangement of numbers, but the subsequent idiom ("tip of the iceberg") also creates the quantitative visual rhetoric to evoke imagery in this example.

The last two state examples in this report were Texas and Colorado. In both cases, the reports avoid any numerical counts to continue the storyline of voter fraud as common. The focus in Texas was on mail-in ballots as problematic. In Colorado, the reporters invoke quantitative rhetoric by simply including the word "multiple," so that text on screen reads: "Multiple cases of dead people voting." Closing out the narrative, the Fox \& Friends interviewer stated, "It makes everyone who votes and votes earnestly feel like their vote might matter a little bit less," noting that Pennsylvania and Colorado are key swing states that will decide the presidential election. The commentator confidently made this assertion based on the extrapolation from these four examples, even though it is highly unlikely that these examples provide evidence of any impact of voter fraud on U.S. presidential elections (Goel, Meredith, Morse, Rothschild, \& Shirani-Mehr, 2017).

\section{Avoiding Numbers When Inconvenient}

In other instances, highlighting individual stories with powerful imagery was a design choice that created a visual rhetoric where quantification seemed less visible. Avoiding numbers could involve two practices: ignoring raw number counts or percentages, and invoking quantitative rhetoric. For example, a CNN article on post-election hate crimes reported a mixture of 
percentages and raw numbers for a storyline that hate crimes are growing (Yan, Sgueglia, \& Walker, 2016). The authors noted a raw number count of 867 cases from November 9 to November 18; however, this count did not provide contextual information to understand the quantity relative to previous counts of hate crimes in the United States. Invoking such quantitative rhetoric through words and raw numbers is still a mental-visual task (Cleveland \& McGill, 1984) as the onus of visualizing the size and scale of these numbers is shifted on to the audience. In other words, is 867 a drastic increase? And in a country with over 300 million people, how might readers make sense of what 867 (over ten days) means? Quantitative rhetoric is also invoked by stating that these incidents have been "everywhere - in schools, in places of business like Walmart, on the street," a widespread issue. Because of the omission of the relative nature of these numbers, a larger scope is absent from the report. Percentages might provide more context to make meaning of the scope of hate crimes during this time period.

In another point of this article, the authors provided a percentage while omitting raw number counts, stating "FBI statistics for 2015 showed a 67\% increase in hate crimes against Muslim Americans." Without providing raw number counts to which the percentage is referencing, it is again difficult to determine the scope of hate crimes. Invoking quantitative rhetoric, the authors then go on to state, "Hate crimes against Jewish people, African Americans and LGBT individuals also increased," to imply a widespread issue increasingly affecting minoritized groups of people. Finally, the authors centered visual rhetoric by presenting 18 individual stories, back-toback, that focus on cases of intimidation and violence after the 2016 election, followed by 3 stories about attacks on Trump supporters. These detailed individual cases serve as stories that might be extrapolated by the reader as disturbing interactions that are part of the larger body of cases occurring.

This strategy to present a percentage with no connection to raw number count (and vice versa) commonly appears in news reports. There are many ways to create quantitative visual rhetoric - this one involves supporting a narrative by omitting a larger scope of the data (i.e., raw number counts or percentages). Intentional inclusion or exclusion of numbers or quantitative words, all shape the meaning. That is, quantitative visual rhetoric is not just what you show, but also what you do not show (and could show).

\section{DISCUSSION}

After assessing the four key design choices, we argue that in a media ecology dominated by the dynamic and demanding digital change and capitalistic motivations, the expectations of sensational news cycles have led to fast and thrilling news generation (McNair, 2017). As digital tools and technologies enter everyday lived experiences, they start to blend with each other to a discernible degree. More adolescent and young adults, across the world, are exploring news through digital sources that blur the distance between media and lifeworld (Mitchell et al., 2018). Imagining life without it being intertwined with some form of informational media is becoming difficult. This underscores the importance of media literacy across K-12, higher education, and even lifelong learning. These changing trends highlight the increasing overlap between the goals of media literacy and democratic education. It is becoming unlikely to prepare people for a future immersed in digitality without equating media literacy with education (Mihailidis, 2006).

There is nothing new that we can say about the importance of focusing on media literacy throughout education that media literacy scholars and educators have not already said. (Baran, 2010; Hobbs, 2007; Mihailidis, 2006; Livingstone, 2004; Potter, 2013). The exigency of 
incorporating media literacy education into disciplinary curriculum across K-12 and in higher education is manifesting itself in global effects of distrust in a media that established itself as an unbiased critic of political, judicial, and social power (Mitchell et al., 2014). Although from our analysis we found that media outlets across the political spectrum produced quantitative visual rhetoric to advance particular storylines, promoting an overall distrust of media sources is not productive for mitigating this issue. Perhaps, then, a goal for media literacy education is to make visible intricacies and subtleties in the content we constantly consume and produce, such as the four design choices we outline in this article. We view quantitative visual rhetoric as one small yet crucial piece of the bigger media literacy repertoire. Therefore, in this section we offer a few takeaways for media literacy education and civic engagement from a quantitative visual rhetoric perspective.

What accompanies numbers? The first takeaway from our analysis of the quantitative visual rhetoric in the media during the 2016 U.S. presidential elections is about the importance of non-quantitative language that accompanies a quantitative rhetoric. Whether it be a visual or predominantly verbal quantitative rhetoric, modifier words shape our meaning of numbers and other quantitative concepts. For this reason, teachers of language arts, science, mathematics, among other subject areas, all carry a responsibility of informing students about how rules and language - the symbol systems - in one subject area shape the symbol systems of others. As we showed in the New York Times and the Wall Street Journal examples, factual and statistically accurate graphs can be manipulated by the language in the labels and legends, the choice of colors, the type of the chart used, among other subtle design features.

Here, readers/viewers need to identify all possible modalities used in a given space and acknowledge what each of them bring to the meaning-making process. This can help identify the extent of variables involved in manipulating meaning and, therefore, becomes the first step in decoding the design choices.

What do quantitative words mean? Our second takeaway is specifically about words that imply quantification. That is, words that represent some form of spatiotemporal countability, measurability, or comparability. For example, few, many, multiple, huge, and low (among other similar words) all offer some form of quantitative understanding to the overall meaning. In a quantitative rhetoric, such words leave a lot of room for manipulation of meaning. For instance, when the word multiple or many is used, technically, it could mean two, two million, or any number more than one, depending on the context. When we read a headline such as "multiple people were arrested," we form a quantitative image in our head that could anchor the actual number anywhere our understanding of the context places it. Similarly, words like more or decrease imply a scale or hierarchy; they do not tell us how we choose to count or create metrics, though. It is also important to note that proportions, ratios, percentages, and fractions do not mean much without reference to a whole - as we showed with the Fox News and CNN examples that only produced percentages without a raw number count (and vice versa). What influences the meaning-making with such words are the social literacy practices in the media that shape how we process these words. As seen in the examples from Fox News, words like hundreds, thousands, and several are common when the actual number may not be as impactful for the purpose of the story.

How to read multimodality? Our third takeaway is to emphasize the relationship between visually-rich quantitative cognitive processes and the rhetoric that takes advantage of this fundamental human trait. Additionally, we want to draw attention to how emotion and feeling are part of an embodied sense-making of quantitative visual rhetoric. 
Visual modes help us comprehend and process numbers. But if someone dishonestly manipulates human psychology to persuade people, people have the right to be aware of such manipulations, be able to assess these practices, and take appropriate counter-action.

Graphs, which can give the appearance of being scientific can increase persuasiveness; even trivial graphs and formulas increase public belief (Tal \& Wansink, 2016). The impact of simple quantitative visual rhetoric on meaning-making has crucial repercussions for media literacy education. We found visual manipulations, such as use of space to imply gap and compare incommensurable items by size using charts, could imply non-existing meaning, thereby helping news outlets lie without getting caught with words.

What do statistics mean? Our fourth, and final, takeaway is to understand the use of statistical concepts of probability and predictability to feed fantasy. Starting from a young age and leading up to adulthood, people often find complex statistical concepts difficult to comprehend (Spiegelhalter, 2010). Concepts of probability and uncertainty can be seen as being misused and misunderstood by people, even in media. As seen in the examples shared from the New York Times and Wall Street Journal, news outlets can use probability and predictability as a fantastic escape for its readers.

Countering the challenge of rampant statistical models and rhetoric in the news media would mean educating people about the subtleties and complexities of the concepts of probability, uncertainty, and predictability. In addition to this, personal understanding of the world that involves theories about causality, influence of past on the future, fate, karma, and other spiritual, pseudoscientific, and even religious notions increase the messiness of statistical concepts. For example, for a person who chooses to believe in a supreme being controlling or determining future outcomes, probability can be irrelevant. Teaching statistical concepts to a world where everyone has folk theories about future and uncertainty raises deeper epistemological concerns that media literacy research needs to acknowledge and address as well.

\section{CONCLUSION}

Across the political spectrum for popular media outlets, we found examples of spatial manipulation, fantasizing with probability, manipulation through data extrapolation, and avoiding numbers when inconvenient. Given these, we argue that the goal through media literacy education is to make visible the intricacies and subtleties in the media that go beyond written or spoken word. This goal is bigger than a subject area or classroom curriculum and has repercussions that can be deeply personal to people. The process of meaning-making is rich with multimodal intertextuality (Kress, 2003). With a focus on words and images, we have only scratched the surface of manipulations. This dynamic and complex interplay of a barrage of sociocultural factors extend a daunting challenge for media literacy educators. It calls for a need to inject media literacy across disciplines and levels of education. 


\section{REFERENCES}

Arana, G. (2015, March 30). Bill O'Reilly lied about rescuing me during Buenos Aires riot, says CBS cameraman. HuffPost. Retrieved from https://www.huffingtonpost.com/2015/03/30/bill-oreilly-lied-falklands n 6970194.html

Baran, S. J. (2010). Introduction to mass communication: Media literacy and culture. New York, NY: McGraw Hill.

Barrett, D. (2016, October 30). FBI in internal feud over Hillary Clinton probe. Wall Street Journal. Retrieved from https://www.wsj.com/articles/laptop-may-include-thousands-ofemails-linked-to-hillary-clintons-private-server-1477854957

Bookstein, F. L. (2009). How quantification persuades when it persuades. Biological Theory 4(2), 132-147.

Cleveland, W. S., \& McGill, R. (1984). Graphical perception: Theory, experimentation, and application to the development of graphical methods. Journal of the American Statistical Association, 79(387), 531-554.

Craig, J. C. (2017). Real fantasies in mathematics education: Numeracy, quantitative reasoners, and transdisciplinary wicked problems (Doctoral dissertation). Retrieved from ProQuest Dissertations and Theses database. (UMI No. 10621502).

Foss, S. K. (2004). Framing the study of visual rhetoric: Toward a transformation of rhetorical theory. Defining Visual Rhetorics, 303-313.

Fox News Insider. (2016, October 21). Dead people registering? Examples of voter fraud in key swing states. Fox News. Retrieved from http://insider.foxnews.com/2016/10/21/deadpeople-registering-reporter-lays-out-examples-voter-fraud-swing-states

Gibson, J. J. (2014). The ecological approach to visual perception: classic edition. Psychology Press.

Goel, S., Meredith, M., Morse, M., Rothschild, D., \& Shirani-Mehr, H. (2017, January 13). One Person, One Vote: Estimating the Prevalence of Double Voting in U.S. presidential Elections. Working Paper. Retrieved from https://polmeth.polisci.wisc.edu/Papers/2votes_v7.pdf

Hobbs, R. (2007). Reading the media: Media literacy in high school English. Teachers College Press. New York, NY: Teachers College Press.

Holsanova, J., \& Nord, A. (2010). Multimodal design: Media structures, media principles and users' meaning-making in printed and digital media (pp. 81-103). Frankfurt/New York: Campus.

Jewitt, C. (Ed.). (2014). The Routledge handbook of multimodal analysis. London: Routledge.

Katz, J. (2016, November 8). Who will be president? New York Times. Retrieved from https://www.nytimes.com/interactive/2016/upshot/presidential-polls-forecast.html

Kostelnick, C. (2007). The visual rhetoric of data displays: The conundrum of clarity. IEEE Transactions on Professional Communication, 50(4), 280-294.

Kress, G. R. (2003). Literacy in the new media age. Psychology Press.

Kress, G. (2004). Reading images: Multimodality, representation and new media. Information Design Journal, 12(2), 110-119.

Kress, G. R., \& Van Leeuwen, T. (1996). Reading images: The grammar of visual design. Psychology Press. 
Lemke, J. (2013). Toward critical multimedia literacy: Technology, research, and politics. In M. McKenna, L. Labbo, R. Kieffer, \& D Reinking (Eds), The international handbook of literacy and technology: Volume two (pp. 3-14). New York: Routledge.

Lemke, J. (2009). Multimodal genres and transmedia traversals: Social semiotics and the political economy of the sign. Semiotica, 2009(173), 283-297.

Leu, D. J., Everett-Cacopardo, H., Zawilinski, L., McVerry, G., \& O’Byrne, W. I. (2012). New Literacies of online reading comprehension. In C. Chapelle (Ed.), The encyclopedia of applied linguistics. New York: Wiley.

Livingstone, S. (2004). Media literacy and the challenge of new information and communication technologies. The Communication Review, 7(1), 3-14.

McNair, B. (2017). Fake news: Falsehood, fabrication and fantasy in journalism. New York: Routledge.

Mihailidis, P. (2006). Media literacy in journalism/mass communication education: Can the United States learn from Sweden? Journalism \& Mass Communication Educator, 60(4), 415 428.

Mitchell, A., Gottfried, J., Kiley, J., \& Matsa, K. E. (2014, October 21). Political Polarization \& Media Habits. Retrieved March 27, 2018, from http://www.journalism.org/2014/10/21/political-polarization-media-habits/

Mitchell, A., Simmons, K., Matsa, K. E., \& Silver, L. (2018, January 11). Publics Globally Want Unbiased News Coverage, but Are Divided on Whether Their News Media Deliver. Retrieved March 27, 2018, from http://www.pewglobal.org/2018/01/11/publics-globallywant-unbiased-news-coverage-but-are-divided-on-whether-their-news-media-deliver/

Penzenstadler, N., \& Page, S. (2016, June 1). Exclusive: Trump's 3,500 lawsuits unprecedented for a presidential nominee. USA Today. Retrieved from https://www.usatoday.com/story/news/politics/elections/2016/06/01/donald-trumplawsuits-legal-battles/84995854/

Peters, C., \& Broersma, M. J. (Eds.). (2013). Rethinking journalism: Trust and participation in a transformed news landscape. London/New York: Routledge.

Porter, T. M. (1995). Trust in numbers: The pursuit of objectivity in science and public life. Princeton, NJ: Princeton University Press.

Potter, W. J. (2013). Media literacy. Thousand Oaks, CA: Sage Publications.

Rawlins, J. D., \& Wilson, G. D. (2014). Agency and interactive data displays: Internet graphics as co-created rhetorical spaces, Technical Communication Quarterly, 23(4), 303-322

Schmit, J. (2010). Teaching statistical literacy as a quantitative rhetoric course. Retrieved from http://www.statlit.org/pdf/2010SchmitASA.PDF

Spiegelhalter, D. (2010, November). Why do people find probability unintuitive and difficult? NRICH-University of Cambridge. Retrieved from https://nrich.maths.org/7326

Starr, K. (1998). The Starr Report: The findings of independent counsel Kenneth W. Starr on president Clinton and the Lewinsky affair. Washington, DC: Public Affairs.

Tal, A., \& Wansink, B. (2016). Blinded with science: Trivial graphs and formulas increase ad persuasiveness and belief in product efficacy, Public Understanding of Science, 25(1), $117-125$.

Tufte, E. R. (1983). The visual display of quantitative information. Cheshire, CT: Graphic Press

Yan, H., Sgueglia, K., \& Walker, K. (2016, November 10). 'Make America White Again': Hate speech and crimes post-election. $C N N$. Retrieved from https://www.cnn.com/2016/11/10/us/post-election-hate-crimes-and-fears-trnd/index.html 